\title{
Effects of Skill Training on the Sprint Performance of Secondary School Athletes
}

\author{
Godfrey C. Nji ${ }^{1}$, Oluchukwu Precious Udeh ${ }^{1}$, Robert C. Ezeanwu ${ }^{2}$, Oliver Rotachukwu Ngwoke ${ }^{1}$, \\ Benjamin Ijuo Ejeh ${ }^{1}$, Badaru Jinedu Umar ${ }^{1} \&$ John Ezebuilo Ogugua ${ }^{1}$ \\ ${ }^{1}$ Department of Human Kinetics and Health Education, University of Nigeria Nsukka, Nigeria \\ ${ }^{2}$ Centre for Entrepreneurship and Development Research, University of Nigeria, Nsukka, Nigeria \\ Correspondence: Oliver Rotachukwu Ngwoke, Department of Human Kinetics and Health Education, University \\ of Nigeria, Nsukka, Nigeria. E-mail: oliver.ngwoke@unn.edu.ng
}

Received: September 10, 2019 Accepted: November 28, 2019 Online Published: December 12, 2019

doi:10.5539/gjhs.v11n14p91 URL: https://doi.org/10.5539/gjhs.v11n14p91

\begin{abstract}
The purpose of this study was to determine the effect of skill training on sprint performance of secondary school athletes. Purposive sampling was used to select Model Secondary School, Nsukka. Thirteen (13) athletes of the chosen secondary school participated in the study, eight (8) male and five (5) female athletes. The quasi-experimental research design was adopted for this study. The instruments for data collection were a training schedule prepared by the researchers and a stopwatch. The analysis of the data was done using the Statistical Package for Social Sciences (SPSS) batch system version 21. The data collected were analysed and presented in tables. The statistical tools used were mean, standard deviation and the null hypotheses were tested using ANCOVA. The subjects recorded a residual score of $0.75 \mathrm{~s}$ for the return time and $0.655 \mathrm{~ms}^{-1}$ for speed which indicates an improvement on the return time and the speed respectively. There was a significant difference in the mean pre-test and post-test scores based on gender. The study concludes that skill training improved the sprint performance of athletes, it is considered paramount for successful performance and further recommends that student-athletes should be properly trained before enrolling in any competition.
\end{abstract}

Keywords: athletes, performance, skill training, sprints

\section{Introduction}

Sprint performance is one which cuts across different sports activities which involves running of any kind and can be quantified in terms of time, distance, speed and acceleration. Coaches, athletes, physical educators and the spectators expect the athletes to perform excellently. Thus, the great necessity to train the athletes excellently and in all dimensions for such output needed. The coach has a major responsibility to ensure that the athlete is adequately trained (Marshall \& Turner, 2016). Sprints are referred to as short distance races due to the distance to be covered. It predominantly implies accelerating forward on level ground (Morin, Edouard, \& Samozino, 2011). Sprints involve four (4) sequential skills which are: the start, the running strides, the coast and the finish. In this study, the term sprints refer to short distance races. This study will focus on the $100 \mathrm{~m}$ race. The $100 \mathrm{~m}$ race is a short distance race that requires speed and power. The 100-m event is the standard measure of the extreme speed capabilities of human bipedal locomotion and defines the "world's fastest human" for a given time period (Dick, 1999; Morin, Bourdin, Edouard, Peyrot, Samozino \& Lacour, 2012). According to Nelson (2016), track-and-field athletics are the oldest forms of organized sport, having developed out of the most basic human activities - running, walking, jumping, and throwing. Athletics is categorized into two broad groups: Track and field athletics. Track athletics are all running events held on the track which fall into three broad distance categories: sprints, middle-distance, and long-distance track events. Relay races feature teams comprising four runners each, who must pass a baton to their team-mate after a specified distance with the aim of being the first team to finish. Hurdling events and the steeplechase are track events which involve that athletes must clear obstacles on the track during the race. The results of racing events are decided by finishing position (or time, where measured). The field events are those athletics activities carried out outside the tracks. They come in two types: jumping and throwing events. In throwing events, athletes are measured by the distance they hurl the equipment, with the common events being the shot put, discus, javelin, and hammer throw. There are four common jumping events: the long jump and triple jump which measurement of the horizontal distance covered is taken, while for the high jump and pole vault 
the height or vertical distance achieved determines the results (Wikipedia, 2017). Combined events, which include the decathlon (typically competed by men) and heptathlon (typically competed by women), are competitions where athletes compete in a number of different track and field events, with each performance going toward a final points tally. Athletics is one of the most commonly competed sports in the world (Nelson, 2016). Individuals who engage in athletic activities are referred to as athletes. A person trained to compete in sports or exercises involving physical strength, speed, or endurance is referred to as an athlete. An athlete should be physically fit, mentally stable, socially fit and emotionally fit. He should possess teachable skills and should be one that regards authority. Thus, sports seek to harness the emotions for the best. With this understanding, one can say that an athlete is one, who engages in athletic activities possessing physical fitness and socially acceptable values. An athlete can have either intrinsic or extrinsic motivation or both. The passion of the athlete, his goals, interests and aspirations constitute his intrinsic motivation while the rewards, recognition, his coach, teammates, opponents, availability of facilities and equipment can provide him with the extrinsic, that is external, motivation to participate in athletics. Technically, an individual needs to be trained for such an individual to attain the required necessities to perform in any given task.

Training is a process that tries to improve skills or add to the existing level of knowledge so that the individual is better equipped to do his present job or to mould him to be fit for a higher job involving higher responsibilities (Kalra\& Bhatia, n.d). For an athlete to constantly improve on his performance, such athlete must be trained constantly (Bangsbo, Mohr, Poulsen, Perez-Gomez, \& Krustrop, 2006). Winterton, Le Deist, and Stringfellow, (2006) referred skill as a level of performance, in the sense of accuracy and speed in performing particular tasks. And this accuracy can be attained through training. According to the National Athletics Trainers' Association (2017), Athletic training encompasses the prevention, examination, diagnosis, treatment and rehabilitation of emergent, acute or chronic injuries and medical conditions. It is the practice of physical conditioning and reconditioning of athletes and prevention of injuries incurred by them. It is the physical and mental conditioning program used by athletes to increase their proficiency in sports (Medical Dictionary Online, 2009). Various factors can affect the acquisition of skills and these factors can be based on the skill and its method of acquisition and the learner. Skill acquisition depends on levels of keenness, confidence, competitiveness, self-esteem and relations with others and even level of aggression. Training programmes are designed to improve performance by developing the appropriate energy sources, increasing muscular structures, and improving neuro-muscular skill patterns. Understanding of the performance pattern from which the training pattern is to be derived is often geared to the experience and intuition of the trainer or physical coach.

The coach or trainer involved in training the athlete plays a major role in ensuring that the athlete performs beyond expectations. Coaches have the greatest amount of influence and responsibility for every aspect of the athletic program (Johnson, Wojnar, Price, Foley, Moon, Esposito, \& Cromartie, 2011). Differences among coaching styles through the characteristics of personality, knowledge, experience, communication skills, team leadership, and motivation methodology, can directly influence the same characteristics in the athletes (Barić \& Bucik, 2009). Coaches who show sufficient knowledge in the technical skills of sports movements are better able to teach athletes correctly and decrease the number of injuries from improper form and technique (Johnson et al., 2011). Thus, an ideal trainer is one who runs a detailed programme of events during the training schedule of athletes. Such training programmes aim to develop the athlete in readiness as regards to an upcoming competition or the career of the athlete and enhance an athlete's performance. Therefore, the activities included in the programme should be such that are specific to aid in the achievement of the objectives of the training. The coach plays a major role in ensuring the success of the athlete. In addition to the coach and the athlete, several factors abound that influence the athletic performance of the athlete.

For athletes to perform maximally, there should be a detailed programme of training which accounts for preparing the athlete for any competition in all ramifications. Such training programmes should be in line with training principles and should aim at keeping such an athlete in an always ready situation. Worthy of note is the fact that the stated ideals of training have not been fully adopted as the training patterns for athletes in Nigeria especially as it concerns secondary school competitions. In most secondary schools, the athletes are only awakened to training when the competition is close thus, such athletes are subjected to rigorous and continuous training from the day information concerning the competition is gotten till the day of the competition. In most cases, the obtainable practice in secondary school is to bring out the students who seem interested in the competition or those who are or appear athletic, these students are made to run and at the end, the best runners are selected to compete in the upcoming competition. These students are oftentimes made to miss their classes. There has not exactly been a standard practice of drilling the athletes on the basic skills of sprinting. There are rules, strategies and tactics that can equip the athlete to perform maximally at any given competition while being confident that he has learnt the 
required skills. The ability of the athlete to understand these basics enables him to have control over his performance.

This obtainable pattern of training in most Nigerian secondary schools inculcate into the athletes the idea that there is no basic need for constant training as they eventually perform well at the competition. It also makes them accept the mentality that to be a good sportsman does not have anything to do with obtaining academic knowledge thus seeing sports and academic knowledge as two different bodies of experiences without relationship. The average Nigerian secondary school athlete accepts that winning is the peak point of sports events. In addition, this pattern is responsible for having athletes who suffer various sports injuries as they are not equipped with the rudiments of body mechanics. This anomaly poses a problem in sprints as it restricts the performance of the athletes due to inadequate training and harnessing of skills.

\subsection{Research Questions}

The following research questions have been posed to guide the study:

1) What is the effect of skill training on return time of secondary school athletes in Nsukka Urban?

2) What is the effect of skill training on speed of secondary school athletes in Nsukka Urban?

\subsection{Hypotheses}

HO1: There is no significant difference in the mean pre-test and post-test return time scores of athletes based on gender.

HO2: There is no significant difference in the mean pre-test and post-test speed scores of athletes based on gender

\subsection{Significance of the Study}

It is generally assumed as well as an accepted fact that training in various ways affects the athletic output of the athletes involved. Researchers have also researched the said problem. Thus, this study intends to add to the available literature by discussing the effects of skill training on the sprint performance of secondary school athletes specifically determining its effect on return time and speed of the athletes.

The results of this study will enable the curriculum bodies, sports specialists, sports bodies and organisations, and physical educators to establish and inculcate a standard pattern of training which will serve as a major criterion for any secondary school to qualify for any secondary school competition. This will ensure that the athletes are always ready and in their optimal body state thus paving a way for them to be career athletes thus contributing to the posterity of athletics. The athletes will also benefit from the results as they are able to effectively and properly participate in the $100 \mathrm{~m}$ event at all times and they enjoy their participation in athletics beyond the need for them to just participate and win trophies for their school.

\section{Methods}

The quasi-experimental research design was adopted for the study. Morrison, Cohen, and Manion (2011) defined the quasi-experiment as a study in which the independent variables are isolated, controlled and manipulated to observe the effects on the dependent variable being studied and there is no control group. This design occurs in a natural setting. The quasi-experimental design is also referred to as a field experiment (Morrison, Cohen, \& Manion, 2011). This design was considered suitable for this study as it enabled the researcher to observe the effects of skill training as the independent variable on the dependent variable, the sprint performance of secondary school athletes in Nsukka Urban. The population of the study comprised of the athletes in the secondary schools in Nsukka Urban. There are twenty-one (21) secondary schools in Nsukka urban (Area Inspectorate of Education, 2016). Purposive sampling was adopted in this study to select Model Secondary School, Nsukka. The sample population comprised of thirteen (13) athletes, 8 male and 5 female athletes, of Model Secondary School, Nsukka. The students included in this study met the following criteria for inclusion: they are registered students of the institution; they are athletes recognized by the school. The instruments for data collection were a training schedule prepared by the researchers titled, Training Schedule on the Skills in 100m race (TSS100) and a stopwatch. The training schedule was made up of two sections. Section A was the training plan containing the details of the skill training. Section B was a scoring sheet with six columns bearing the items: subjects, gender, T1 (pre-test return time for the subjects), S1 (pre-test speed for the subjects), T2 (post-test return time for the subjects) and S2 (post-test speed of the subjects).

The training schedule together with the objectives, research questions and hypothesis was given to five experts (four in Human Kinetics and Health Education and one in Science Education Department). The experts studied the 
instrument to check its appropriateness. They also confirmed the content and face validity of the instrument. Their corrections and suggestions were properly effected before administering the training. The data were collected by observation and the pre-test and post-test values were recorded from the readings of the stopwatch at each time. The return time of the subjects before the training was administered was recorded as RT1 while the return time of the subjects after the training was administered was recorded as RT2. Also, the speed of the subjects before the training was administered was calculated and recorded as S1 while the speed of the subjects after the training was administered was calculated and recorded as S2. The analysis of the data was done using the Statistical Package for Social Sciences (SPSS) batch system version 21. The data collected were analysed and presented in tables. The statistical tools used were mean, standard deviation and the null hypotheses were tested using ANCOVA.

\section{Results}

The results of this study were organised and presented in two parts as thus; data answering the research questions and data testing the null hypotheses.

\subsection{Research Question One}

What is the effect of skill training on return time of secondary school athletes in Nsukka Urban?

Data answering the research question are contained in Table 1 . These data are presented with a brief interpretation of the content.

Table 1.Mean and standard deviation of skill training (S/Training) effect on return time of secondary school athletes $(\mathrm{n}=13)$

\begin{tabular}{lllllll}
\hline & Pre-test & \multicolumn{3}{c}{ Post-test } & \multirow{2}{*}{ SD } & Residualscore \\
\cline { 2 - 5 } & $\mathbf{N}$ & $\bar{X}$ & SD & $\bar{X}$ & & \\
\hline S/Training & 13 & 12.00 & .78 & 11.25 & .92 & 0.75 \\
\hline
\end{tabular}

Data in Table 1 shows that secondary school athletes after the skill training had a mean return time of $11.25 \mathrm{~s}$ and standard deviation of .92 at the post-test against their pre-test mean return time of $12.00 \mathrm{~s}$ and standard deviation of .78. The residual score for the group shows that secondary school athletes had an improved return time of $0.75 \mathrm{~s}$.

\subsection{Research Question Two}

What is the effect of skill training on speed of secondary school athletes in Nsukka urban?

Data answering this research question are contained in Table 2. These data are presented with a brief interpretation of the content.

Table 2. Mean and standard deviation of skill training effect on the speed of secondary school athletes $(n=13)$

\begin{tabular}{|c|c|c|c|c|c|c|}
\hline & \multicolumn{2}{|c|}{ Pre-test } & \multicolumn{2}{|c|}{ Post-test } & \multirow{2}{*}{ SD } & \multirow{2}{*}{ Residualscore } \\
\hline & $\mathbf{N}$ & $\bar{X}$ & SD & $\bar{X}$ & & \\
\hline S/Training & 13 & 8.289 & .55 & 8.944 & .69 & 0.655 \\
\hline
\end{tabular}

Table 2 shows that secondary school athletes after the skill training had a mean speed of $8.944 \mathrm{~ms}-1$ and standard deviation of .69 at the post-test against their pre-test mean speed of $8.289 \mathrm{~ms}^{-1}$ and standard deviation of .55 . The residual score for the group shows that secondary school athletes had an improved speed of $0.655 \mathrm{~ms}^{-1}$.

\subsection{Hypothesis One}

There is no significant difference in the mean pre-test and post-test return time scores of athletes based on gender. 
Table 3. Summary of One-Way ANCOVA of skill training effect on return time among secondary school athletes $(\mathrm{n}=13)$

\begin{tabular}{lllllll}
\hline Source & Sum of squares & $\mathbf{m} / \mathbf{s}$ & $\mathbf{d} / \mathbf{f}$ & $\mathbf{F}$ & Sig. & PAS \\
\hline Pre-test & .424 & .424 & -1 & 3.187 & .11 & .24 \\
Method & 8.829 & 4.41 & 2 & 33.21 & .00 & .87 \\
Gender & 1.271 & 1.27 & 1 & 9.56 & .01 & .49 \\
Error & 1.329 & .133 & -10 & & & \\
\hline
\end{tabular}

$\mathrm{P}<0.05$.

\section{Key}

$\mathrm{M} / \mathrm{s}=$ Mean square;

Sig. = Significance;

PAS $=$ Partial Eta Squared

The analysis of covariance was conducted to determine the effectiveness of skill training to improve participants' return time. The independent variable was skill training intervention and the dependent variable comprised the post-test return time scores of athletes administered after the intervention was completed. Athletes' pre-test return time scores before the skill training intervention were used as a covariate in the analysis.

Preliminary checks were conducted to ensure that there was no violation of the assumptions of normality, linearity, homogeneity of regression slopes and reliable measurement of the covariate. After adjusting for pre-intervention scores (pre-test scores), there was a significant gender difference between the pre-test and post-test scores on the skill training, $F(1,10)=9.56, \mathrm{p}=.01$, partial eta squared $=.49$. Therefore, there is a significant difference in the mean pre-test and post-test return time of the athletes based on gender. There was a weak positive relationship between the pre-test and post-test scores on the skill training as indicated by a partial eta squared value of .24. (see Table 3).

\subsection{Hypothesis Two}

There is no significant difference in the mean pre-test and post-test speed scores of athletes based on gender. Data for testing the hypothesis are represented in table four (4)

Table 4. Summary of One-Way ANCOVA of skill training effect on speed among secondary school athletes ( $\mathrm{n}=13)$

\begin{tabular}{lllllll}
\hline Source & Sum of squares & $\mathbf{m} / \mathbf{s}$ & $\mathbf{d} / \mathbf{f}$ & $\mathbf{F}$ & Sig. & PAS \\
\hline Pre-test & .146 & .146 & 1 & 1.91 & .197 & .16 \\
Method & 5.011 & 2.51 & 2 & 33.21 & .000 & .87 \\
Gender & 1.841 & 1.84 & 1 & 9.56 & .001 & .71 \\
Error & .763 & .076 & 10 & & & \\
\hline
\end{tabular}

$\mathrm{P}<0.05$.

\section{Key}

$\mathrm{M} / \mathrm{s}=$ Mean square;

Sig. $=$ Significance;

PAS $=$ Partial Eta Squared.

The analysis of covariance was conducted to determine the effectiveness of skill training to improve participants' speed. The independent variable was skill training intervention and the dependent variable comprised the post-test speed scores of athletes administered after the intervention was completed. Athletes' pre-test speed scores before the skill training intervention were used as a covariate in the analysis.

Preliminary checks were conducted to ensure that there was no violation of the assumptions of normality, linearity, homogeneity of regression slopes and reliable measurement of the covariate. After adjusting for pre-intervention 
scores (pre-test scores), there was a significant gender difference between the pre-test and post-test scores on the skill training, $F(1,10)=24.14, \mathrm{p}=.001$, partial eta squared $=.71$. Therefore, there is a significant difference in the mean pre-test and post-test speed scores of athletes based on gender. There was a weak positive relationship between the pre-test and post-test scores on the skill training as indicated by a partial eta squared value of .16. (see Table 4).

\section{Discussion of Findings}

The study determined the effect of skill training on sprint performance of secondary school athletes. Table one shows the residual score for the group as $0.75 \mathrm{~s}$ which shows that the secondary school athletes had an improved return time of $0.75 \mathrm{~s}$ after the administration of skill training. This finding shows that skill training in $100 \mathrm{~m}$ has a positive effect on the return time of the secondary school athletes. This result was expected as skill training makes for proficiency and efficiency in executing the skills of $100 \mathrm{~m}$ thus greater result. The athletes gained a mean time of $0.75 \mathrm{~s}$; this means that after the administration of training they covered the same distance over a shorter time. Given that the athletes were trained to maintain a balance between stride length and frequency, their performance improved. This is in line with the findings of Kryzsztof and Mero (2013) and Maćkała, Fostiak and Kowalski (2015) that stride length and stride frequency account for a faster sprinting.

Table two shows the residual score for the group as $0.655 \mathrm{~ms}-1$ which shows that the secondary school athletes had an improved speed of $0.655 \mathrm{~ms}-1$ after the administration of the skill training. This result also indicates that the skill training in $100 \mathrm{~m}$ has a positive effect on the speed of the secondary school athletes. The athletes gained speed after the training. This result was expected as the athletes were trained to maximise the frequency and length of their strides. This finding is in line with Ferro et al. (2001) who highlighted that sprinting speed is defined with frequency and length of strides. This finding also agrees that speed is a skill that can be improved by training against the widespread notion of it being an inherited trait (Schiffer, 2011).

Table three shows that there is a significant difference in the mean pre-test and post-test return time of the athletes based on gender. This result shows that the gender of the athletes affected their return time even after receiving the same training. This result shows that the male athletes had a slightly higher improved return time than the female athletes. This result was expected given that the body construct of the males and females is different. This finding contradicts the findings of Lippi,Banfi, Favaloro, Rittweger, and Maffulli (2008) that female athletes showed a higher improvement over males. But it is in line with the findings of Mangine et al. (2008) that the differences that exist in absolute muscular mass, strength, and quality favour male athletes. This finding could mean that to attain the same level of improvement as the male athletes, there may be a need for more intensive training for the female athletes. The physical educator should have an understanding of this difference so as not to expect the same results from the male and female athletes at the same time.

Table four shows that there is a significant difference in the mean pre-test and post-test speed of the athletes based on gender. This finding shows that a difference exists in the mean speed of the male and female athletes even after undergoing the same training. According to the results, the male athletes had a slightly higher improved speed after the training. This result of the significant difference in the mean was expected and could be related to the morphological differences of the male and female athletes. This finding is in line with Kryzsztof and Mero (2013) who established the relevance of the morphological characteristics on running speed. Thus, the physical educator should be armed with this information to avoid overexerting the muscles of the female athletes while expecting the same results with the males.

\section{Conclusions}

Skill training on $100 \mathrm{~m}$ sprint improves on the return time of secondary school athletes. Skill training on $100 \mathrm{~m}$ sprint has an enhancing effect on the speed of secondary school athletes. Gender has an effect on the return time of the secondary school athletes both before and after the administration of skill training. Gender influences the speed of secondary school athletes before and after the administration of skill training. A standard training programme for $100 \mathrm{~m}$ sprint should be adopted in secondary schools so as to expose the athletes to the rudiments of the event. Organizations and associations responsible for the administration of competitive sports at secondary school level should develop and implement a policy which mandates schools to properly train their students before enrolling in any competition. Properly trained physical educators should be in charge of coordinating athletic events at the secondary schools.

\section{Competing Interests Statement}

The authors declare that there are no competing or potential conflicts of interest. 


\section{References}

Bangsbo, J., Mohr, M., Poulsen, A., Perez-Gomez, J., \& Krustrup, P. (2006). Training and Testing the Elite Athlete. Journal on Exercise Science and Fitness, 4(1).

Barić, R., \& Bucik, V. (2009). Motivational differences in athletes trained by coaches of different motivational and leadership profiles. Kinesiology, 41(2), 181-194.

Cohen, L., Manion, L., \& Morrison, K. (2011). Research Methods in Education, Seventh Edition. Hampshire: Ashford Colour Press Ltd.

Dick, F. W. (1999). Development of maximum sprinting speed. Track Technique, 109, 3475-3480. Retrieved from https://elitetrack.com/article_files/maximumspeed.pdf

Ferro, A., Rivera, A., \& Pagola, I. (2001). Biomechanical analysis of the 7th IAAF World Championships in Athletics Seville 1999. New Studies in Athletics, (1,2), 25-60

Johnson, S. R., Wojnar, P. J., Price, W. J., Foley, T. J., Moon, J. R., Esposito, E. N., \& Cromartie, F. J. (2011). A coach's responsibility: Learning how to prepare athletes for peak performance. Sport Journal, 14(1), 1-3.

Kalra, R., \& Bhatia, M. (2008). Training: Concepts and Methods. Retrieved February 8, 2017, from http://www.indianmba.com/faculty_column/Fc797/fc797.html

Krzysztof, M., \& Mero, A. (2013). A Kinematics analysis of three best $100 \mathrm{~m}$ performances ever. Journal of Human Kinetics, 36, 149-160. https://doi.org/10.2478/hukin-2013-0015

Lippi, G., Banfi, G., Favaloro, E., Rittweger, E., \& Maffulli, N. (2008). Updates on improvement of human athletic performance: focus on world records in athletics. British Medical Bulletin, 87(1), 7-15. https://doi.org/10.1093/bmb/ldn029

Maćkała, K., Fostiak, M., \& Kowalski, K. (2015). Selected Determinants of Acceleration in the 100m Sprint. Journal of Human Kinetics, 45, 135-148. https://doi.org/10.1515/hukin-2015-0014

Mangine, G. T., Fukuda, D. H., LaMonica, M. B., Gonzalez, A. M., Wells, A. J., Townsend, J. R., ... Hoffman, J. R. (2014). Influence of Gender and Muscle Architecture Asymmetry on Jump and Sprint Performance. Journal of Sports Science and Medicine, 13.

Medical Dictionary Online (2009). Athletic Training. Retrieved February 15, 2017, from http://medical-dictionary.thefreedictionary.com/athletic+training

Morin, J. B., Bourdin, M., Edouard, P., Peyrot, N., \& Samozino, P. (2012). Mechanical determinants of 100-m sprint running performance. European Journal of Applied Physiology, 112(11), 3921-3930. https://doi.org/10.1007/s00421-012-2379-8

Morin, J. B., Edouard, P., \& Samozino, P. (2011). Technical ability of force application as a determinant factor of sprint performance. Medical Science on Sports Exercise, 43(9), 1680-1688. https://doi.org/10.1249/MSS.0b013e318216ea37

National Athletics Trainers' Association (NATA). (2017). Athletic Training. Retrieved February 13, 2017, from https://www.nata.org/about/athletic-training

Nelson, B. (2016). Athletics. Retrieved November 27, 2019, from https://www.britannica.com/sports/athletics

Schiffer, J. (2011). Training to overcome the speed plateau.New Studies in Athletics, 26(1/2).

Wikipedia. (2017). Athletics (Physical culture). Retrieved May 20, 2017, from https://en.m.wikipedia.org/wiki/Sport_of_athletics

Winterton, J., Le Deist, F. D., \& Stringfellow, E. (2006). Typology of knowledge, skills and competences: clarification of the concept and prototype. Cedefop Reference series, 64.

\section{Copyrights}

Copyright for this article is retained by the author(s), with first publication rights granted to the journal.

This is an open-access article distributed under the terms and conditions of the Creative Commons Attribution license (http://creativecommons.org/licenses/by/4.0/). 